\title{
ASSESSMENT OF PREMATURITY BY BIRTH WEIGHT, CROWN-RUMP LENGTH, AND HEAD CIRCUMFERENCE
}

\author{
BY \\ RICHARD W. B. ELLIS \\ From the Department of Child Life and Health, University of Edinburgh \\ WITH STATISTICAL ANALYSES
}

\author{
BY \\ D. N. LAWLEY \\ Reader in Statistics, University of Edinburgh
}

In view of the importance now attached to the care of the premature infant, it is highly desirable that stock should be taken of the definitions and classifications in general use, and that the possibility of their improvement should be frequently reviewed. Whilst it is generally recognized that the prospects of survival depend to a much greater extent on functional maturity, e.g. of respiration, digestion, and temperature regulation than they do on any single body measurement, it is likely that objective measurement will always play a certain part in the assessment of both full term and premature infants. In the classification of prematures for record purposes and for comparison of results obtained in different clinics, objective measurement is still essential. To be of service to the clinician, such measurements must be ones, which may be made on the living infant with reasonable accuracy, and ones which do not involve dangerous exposure or manipulation. Those which can readily be applied in the home by nursing personnel will havea wider application than those requiring specialized techniques or apparatus, though these latter may prove of greater value under hospital conditions. A vast amount of data on measurements of premature infants has already accumulated. Scammon and Calkins (1929) who reviewed much of the earlier literature and added some thousands of personal observations, estimated that at least 160,000 measurements had been published up to that time, relating to more than 100 body measurements. It may at first appear surprising that relatively little of this data has been generally used by clinicians for the assessment of prematurity, and that in the majority of clinics birth weight remains the sole or major criterion for classification.

Further examination of the data, much of which derives from post-mortem examination, however, at once emphasizes the differences between examination of living infants and those which have been preserved, injected or at least rendered permanently immobile. Foot-length, for example, which Streeter (1920) found useful as an additional control of gestational age, does not lend itself to accurate measurement in the living infant, whilst circumferential measurements of chest and abdomen are affected by respiration, abdominal distention and movement to an extent which introduces a considerable error. Nevertheless disproportion between head and chest circumference is sometimes taken as an additional indication of prematurity (Reiche, 1916; Dunham, 1948). With regard to head measurements, which will be considered further, it must be remembered that necropsy material examined by pathologists and anatomists is likely to be heavily weighted by stillbirths or birth-deaths in which a greater degree of head moulding or cranial damage is to be expected than in living infants. Perhaps most important of all, much of the published data is related to a single measurement (e.g. total height or crown'heel length), and the estimate of gestational age is often arbitrary, or based on criteria which would no longer be regarded as wholly acceptable.

\section{Gestational Age}

In the last analysis, prematurity represents an abnormally short period of intra-uterine life. Since it is seldom possible to obtain a reliable coital history, the calculation of gestational age is necessarily based on the menstrual history, the expected date of delivery being computed as 10 lunar months from the first day of the last menstrual period. This can only be regarded as accurate to approximately a week less or more than the 
expected date when previous menstruation has been regular and the cycle of normal duration, and when the dates of the last menstruation can be stated accurately. Even then, occasional cases will occur when a month's error is introduced, either by a period having been missed immediately before conception, or when post-conceptional bleeding occurs at the normal time of the next menstrual period. The history is most likely to be accurate in women of good intelligence attending for antenatal supervision soon after pregnancy is first suspected. With the present facilities for early antenatal care, and the emphasis laid on a careful history taken at the first visit, it is, however, possible to estimate the duration of pregnancy with reasonable accuracy in a considerable proportion of cases. In the present investigation, gestational age has been used as the major criterion of prematurity, and only those cases where the estimated date of delivery was not in doubt have been included.

\section{Birth Weight}

Since by international convention (International Committee, Geneva, 1937) an infant weighing $2,500 \mathrm{~g}$. $\left(5 \frac{1}{2} \mathrm{lb}\right.$.) or less at birth is regarded as premature, birth weight has come to be looked on by clinicians with a somewhat exaggerated respect as an index of prematurity. Weight has the practical merit that, if proper precautions are observed and reliable scales are used, it can be accurately measured by nursing personnel. The errors introduced by the passage of urine or meconium during or shortly after birth, and variations in the length of cord attached, are comparatively slight; on the other hand, if the first weighing is not made within 24 hours of birth, it may vary substantially from the true birth weight.

Whilst the arbitrary standard of $2,500 \mathrm{~g}$. has considerable practical value, examination of any large series of cases in which gestational age is accurately known will show instances of full term infants weighing less than $2,500 \mathrm{~g}$. at birth, and of premature infants weighing more. The conception of ' fat and lean foetuses' (Barcroft, 1946) is borne out by Ylppö's (1919) observation that foetuses of the same crown-heel length might show a variation of $100 \%$ in weight, whilst evidence is accumulating (Thomson, 1951) to show that the scatter in birth weight which is so striking in full term infants appears earlier in foetal life than was previously supposed. There is, therefore, considerable risk in assessing prematurity on birth weight alone, or in adopting an arbitrary weight standard as the lower limit of viability. Thus Steiner and Pomerance (1950) found in groups of prematures weighing 1,000 to 1,499 g., but of different gestational ages, that the mortality was $63.3 \%$ in those of less than 29 weeks' maturity and $21.5 \%$ in those of 34 to 37 weeks, although the mean weights of the two groups were almost identical $(1,232$ and $1,234 \mathrm{~g}$. respectively). Reardon, Wilson, and Graham (1951) also emphasize that the expectation of life may be better in more mature infants of $3 \mathrm{lb}$. $(1,360 \mathrm{~g}$.) than in less mature ones of $4 \mathrm{lb}$. $(1,814 \mathrm{~g}$.) and that race and sex may influence birth weight of infants of the same bone-age or maturity.

\section{Measurements of Length}

The foetal measurement which has received most attention by anatomists is total height (crown-heel length), Scammon and Calkins (1929) estimating that ' fully $90 \%$ of the tens of thousands of printed observations of the various dimensions of the body, its weight and volume, and of the weights and dimensions of its various parts in the foetal period .... are recorded with respect to crown-heel length and without reference to crown-rump length.' Crosse (1945) states that crown-heel length provides the most reliable index of gestational age and quotes $18 \frac{1}{2}$ in. $(47 \mathrm{~cm}$.) or less as an indication of prematurity. There is, however, no generally accepted standard of crown-heel length corresponding to the $2,500 \mathrm{~g}$. birth weight. Peckham (1938) states that in the Johns Hopkins Hospital the combination of weight less than $2,500 \mathrm{~g}$. and crownheel length less than $45 \mathrm{~cm}$. has for long been used as the standard of prematurity, but concluded that definitions based on weight or length alone, or on both, were grossly inaccurate, and that allowance should be made for race, sex, birth-rank, and maternal age. (The low standard of $45 \mathrm{~cm}$. crownheel length is presumably related to the fact that the clinic serves a mixed racial population, and that negro infants tend to be smaller than white of the same gestational age). Dunham (1948) takes 47 $\mathrm{cm}$. or less as one criterion which, together with others, indicates or suggests prematurity, and Potter and Adair (1949) classify as viable prematures those with two of the following features: crown-heel length of 35.0 to $46.9 \mathrm{~cm}$., birth weight 1,000 to 2,499 g., and gestational age 29 through 38 weeks. Reardon et al. (1951) quote the United States Bureau of the Census and the Children's Bureau as defining as premature any baby less than $5 \frac{1}{2} \mathrm{lb} .(2,500 \mathrm{~g}$.) in weight and less than 18 in. $(45.7 \mathrm{~cm}$.) in length, with a head circumference of less than $13 \mathrm{in} .(33 \mathrm{~cm}$.) and with a gestation period of 28 to 37 weeks. Here again the figure $45.7 \mathrm{~cm}$. may be assumed to have been based on measurements of a mixed racial population and cannot be taken as necessarily applying to Great Britain.

A point which does not appear to have been 
sufficiently emphasized, since it does not apply to necropsy material, is the practical difficulty of obtaining a reliable crown-heel measurement in some of the smaller living prematures and occasionally in full term infants. In our own experience, it was found that 'pressing the knee down on the mattress with the feet dorsiflexed ', as described by Crosse (1945), would in some cases, admittedly only a small proportion of the total, result either in distortion of the spine which could not be overcome by manipulation (and which might be overlooked if the infant was not examined naked), or risk of trauma, or an amount of manipulation which was not in the best interests of the infant. Measurements made in two stages, on the other hand, without using a measuring board, were too inaccurate to be of value, and there were gross discrepancies between the measurements made routinely by the nursing staff, and those obtained by a pair of trained observers on the same infants. As an alternative, measurement of crownrump length on the measuring board was found to have considerable practical advantages which were felt to outweigh the fact that, as a necropsy measurement, the relative variation observed in measurements of crown-rump length has been shown to be greater than in those of crown-heel length (Scammon and Calkins, 1929). The technique is described below.

The measurement of crown-rump length of premature infants appears to have been little employed by clinicians although Grulee and Sanford (1948) state that it is a more accurate measurement than body length, and, since the appearance of Streeter's (1920) monograph, it has been used to an increasing extent by embryologists and pathologists. Since sitting height in addition to total height is now frequently included in the measurement of older infants and children, it appeared additionally important to assess the value of this measurement in premature infants. It should be kept in mind, however, that when measurements of either crown-heel or crown-rump length are used in growth studies, both involve a series of measurements of structures which are growing in different directions or dimensions. Thus crown-rump length involves head-height and spine-length (a series of chords), height of the innominate bone, and the soft tissues overlying the ischial tuberosity. The measurement of crown-heel length also includes the hip, knee, and ankle, and movements at any of these points, or alterations in muscle tone, may introduce major errors affecting the total measurement.

\section{Head Circumference}

This measurement does not have the same disadvantages as the circumferential measurement of chest or abdomen, and can be carried out with a minimum of exposure and manipulation. In checking measurements made by trained observers against routine measurements made by nursing staff, the correspondence was found to be close; the principal errors introduced were due to the stretching of tape-measures which had been too long in use.

Meredith (1946) in reviewing North American studies of head circumference undertaken from 1890 to 1945 , points out the lack of standardization in the technique of measurement. Thus the landmarks used for measuring occipitofrontal circumference were in some instances the frontal eminences and the most prominent portion of the temporal and occipital regions; in others the tape was passed over (or immediately above) the supra-orbital ridges or glabella anteriorly, while in yet others the measurement was described as the maximum circumference. Scammon and Calkins (1929) defined it as the largest circumference of the head passing through the glabella and the inion, and regarded the mechanical errors in its determination as small. The majority of authors who have made any reference to the degree of pressure employed have specified ' light pressure' with the tape, but the point is of some importance in the case of prematures where firm pressure may produce some alteration in the measurement of a readily compressible skull.

The effect of head moulding on the occipitofrontal circumference cannot be assessed accurately in the individual infant. Calkins (1922), from a study of infants' heads in which moulding was minimal or absent, i.e. in selected Caesarian births and easy breech extractions, calculated a mean of $35 \cdot 2 \mathrm{~cm}$. for unmoulded heads which is significantly greater (by $0.9 \mathrm{~cm}$.) than the composite mean given by Meredith $(34 \cdot 3 \mathrm{~cm}$.). An experimental study by Moloy (1942) also confirmed that the occipitofrontal diameter was decreased by compression. While correction for head moulding is of importance in assessing necropsy material derived from stillbirths and neonatal deaths, it will be remembered that the clinician is primarily concerned with such degrees of head moulding as are compatible with survival, and that for practical purposes unmoulded and grossly moulded heads are exceptional in any unselected series of living infants. In assessing the individual infant, however, it may be assumed that the circumference of the unmoulded head will tend to be greater than that of the head that has been moulded.

Head circumference at birth has been shown to bear some relationship to birth order, economic status, and sex. Thus Bakwin and Bakwin (1934) 
found the mean for first-born infants was $0.3 \mathrm{~cm}$. less than for a comparable series of later-born infants delivered in the same hospitals. Meredith, from the North American data relating to infants of north-west European lineage, concluded that the mean head circumference of infants from the labouring classes was less than that of infants from the professional class. The same author, however, was unable to show any secular changes in head circumference when studies made between 1890 and 1926 were compared with studies made between 1927 and 1945. It is apparent from all studies that the mean measurement for girls at birth is significantly less than for comparable groups of boys. The possible effect of race on head circumference is irrelevant to the present study, though it must obviously be considered where a mixed racial population is under review.

Head circumference is used as a criterion of prematurity by numerous authors, Dunham (1948) from a review of the data accepting a circumference of less than $33 \mathrm{~cm}$. (13 in.) as one measurement probably indicating prematurity.

\section{Present Investigation}

The purpose of the present investigation was to examine three objective measurements, viz. birth weight, crown-rump length, and head circumference in both full-term and premature infants in whom the period of gestation was known, and to consider the application of each as an index of prematurity. A comparison was made of the correlation of birth weight and crown-rump length with gestational age; and the correlation of each of the three measurements with each other was also estimated. Crown-heel length was measured in full term infants and in a proportion of the premature infants in order to estimate the correlation of this measurement with the other three, and to determine whether crown-rump length could usefully be substituted for crown-heel length when the latter measurement was impracticable.

Material. The study was made on 119 living premature infants of 29 to 37 weeks' gestation (inclusive), and 209 full term female and 243 full term male infants. A gestational age of 38 to 42 weeks was regarded as full term. Nineteen pairs of premature twins of like sex were analysed separately. All these infants were born in the Simpson Memorial Maternity Pavilion, Royal Infirmary, Edinburgh, in 1949-51. The series included no negro infants, and though a relatively small number of English and Irish were included, the great majority were of Scottish parentage. Infants with congenital abnormalities liable to affect any of the measurements were excluded, and also infants of diabetic or prediabetic mothers, blood sugar curves being carried out on mothers of infants weighing more than $9 \frac{1}{2}$ lb. Apart from these criteria, and the exclusion of infants dying within a week of birth, and of any cases in which the gestational age was in doubt, which meant in practice that the majority were ' booked ' cases who had attended early in pregnancy for antenatal supervision, the series was otherwise unselected and of mixed birth-rank. No separate analysis of socio-economic status has been made, but the majority of cases would fall into the Registrar General's classes III and IV (occupation of father skilled or semi-skilled labour).

Methods. Birth weight was measured on the first day of life by checked Avery scales measuring to $\frac{1}{4} \mathrm{oz}$. The occipitofrontal circumference of the head was measured with a flexible steel tape to the nearest $1 \mathrm{~mm}$. and checked. Light pressure was used, the tape being fitted to the maximum prominence of the occiput and passed immediately above the supra-orbital ridges. Crown-heel and crown-rump lengths were measured on a standard measuring board, the heel or ischial tuberosity respectively being placed against the stationary foot-piece, and the sliding head-piece adjusted when the infant was correctly positioned. In the case of crown-rump measurements, the stationary footpiece was adapted so that its height was not greater than the infant's thighlength, so that flexion of the knee to a right-angle was possible. (A model suitable for the measurements of older infants, designed by Dr. John Thomson is shown in Fig. 1. Here the stationary foot-piece is of moulded perspex, curved to allow knee-flexion, and lateral flanges attached to the sliding head-piece prevent any rotation of the latter. Both metric and British linear metal measures

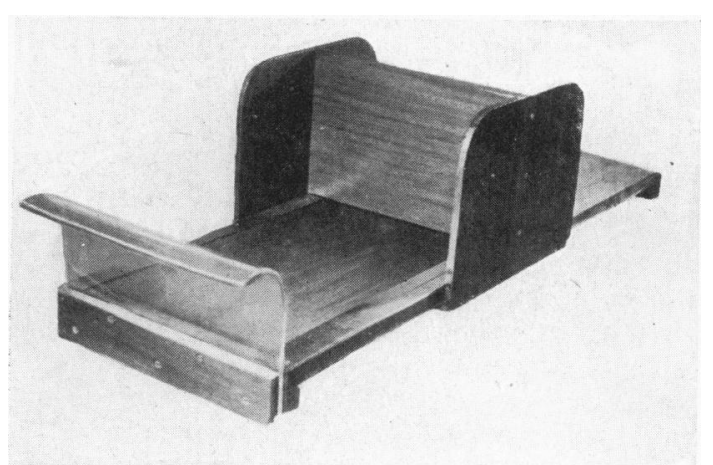

FIG. 1.-Measuring-board for crown-heel and crownrump length (designed by Dr. John Thomson).

are incorporated in the base.) For the accurate measurement of both crown-heel and crown-rump length, it was found that two trained observers were required; in the case of active infants the measurements were apt to be time-consuming. Since the infants were measured naked or with a minimum of covering to avoid overlooking 
malposition of the spine, the prematures were examined in a premature room with a controlled temperature of $82^{\circ} \mathrm{F}$. and the full term infants in a warm nursery. Linear and circumferential measurements were made within six days of birth (mid-point three days). From serial measurements made on the same infants it was considered that, with the possible exception of head circumference, differences observed during the first six days were within the experimental error. (Head circumference was found to show a very slight average decrease on the second to fourth day of life compared with the birth measurement, probably due to reduction of soft-tissue swelling. The changes were not, however, consistent, and when a series of 20 cases born by vertex presentation with birth moulding classified clinically as 'slight' was compared with a series of infants with grossly moulded heads, the average difference between the first and third day measurements was closely similar in the two groups, viz. a decrease of $0.07 \mathrm{~cm}$. and 0.1 $\mathrm{cm}$. respectively).

\section{Results}

Table 1 gives the mean measurements, in metric and British measures, with the standard deviations, for prematures and for male and female full term infants. Owing to the small size of the younger age groups, prematures have been grouped in ranges of two weeks, viz. 29 and 30 weeks, 30 and 31 weeks, up to the age of 37 weeks. 'Full term' infants are those of 38 to 42 weeks.

It will be seen that the means show an increase for each measurement in each successive age-group, and that the standard deviations are relatively large. The large weight increase between 37 weeks, and full term is partly accounted for by 'full term, covering a four-week period, whereas the 37 week infants are drawn from a single week. The means for prematures, which in the case of weight and crown-rump length are higher than those given by Hamilton, Boyd, and Mossman (1945), are to be regarded as those for surviving infants, stillbirths and deaths within the first week having been excluded. The means for full term infants compare closely with those quoted by other authors for white infants, when it is remembered that the definition of full term is not the same in all cases. For birth weight, Stuart and Stevenson (1950) give a percentile rating of 50 to birth weight $7 \mathrm{lb} .8 \mathrm{oz} .(3 \cdot 4 \mathrm{~kg}$.) and $7 \mathrm{lb}$. $6 \frac{1}{2} \mathrm{oz}$. $(3.36 \mathrm{~kg}$.) for male and female full term infants respectively, where infants weighing less than $5 \frac{1}{2} \mathrm{lb}$. were arbitrarily excluded as premature.

The present material was not analysed by social class and birth-rank, but the means for birth weight of full term infants may be compared with those for infants born in the same hospital in 1940 (Dr. J. Thomson, unpublished data), where the analysis is limited to full term first-born infants and divided by social class according to the RegistrarGeneral's classification by occupation of father: viz., III skilled labour including miners; IV semiskilled; and V unskilled labour, there being too few infants in Classes I and II for separate analysis (Table 2).

The mean birth weights of infants in the lowest income group (Class V) are significantly less than those of infants of the same sex in Classes III and IV. It also appears that in the case of male infants, firstborns are on the average of lower birth weight than

TABLE 1

mean Measurements of Head Circumference, Crown-rump Length, and Birth Weight in Premature and FULL TERM INFANTS

\begin{tabular}{|c|c|c|c|c|c|c|c|c|c|c|c|c|c|c|c|c|}
\hline \multirow[b]{2}{*}{$\begin{array}{c}\text { Gesta- } \\
\text { tional } \\
\text { Age } \\
\text { (weeks) }\end{array}$} & \multirow{2}{*}{ ‡ึ } & \multirow[b]{2}{*}{ M. } & \multirow[b]{2}{*}{ F. } & \multirow[b]{2}{*}{ T. } & \multicolumn{4}{|c|}{ Head Circumference } & \multicolumn{4}{|c|}{ Crown-rump Length } & \multicolumn{4}{|c|}{ Birth Weight } \\
\hline & & & & & $\begin{array}{l}\text { Mean } \\
(\mathrm{cm} .)\end{array}$ & $\begin{array}{l}\text { S.D. } \\
\text { (cm.) }\end{array}$ & $\begin{array}{c}\text { Mean } \\
\text { (in.) }\end{array}$ & $\begin{array}{l}\text { S.D. } \\
\text { (in.) }\end{array}$ & $\begin{array}{l}\text { Mean } \\
(\mathrm{cm} .)\end{array}$ & $\begin{array}{l}\text { S.D. } \\
\text { (cm.) }\end{array}$ & $\begin{array}{c}\text { Mean } \\
\text { (in.) }\end{array}$ & $\begin{array}{l}\text { S.D. } \\
\text { (in.) }\end{array}$ & $\begin{array}{c}\text { Mean } \\
\text { (g.) }\end{array}$ & $\begin{array}{l}\text { S.D. } \\
\text { (g.) }\end{array}$ & $\begin{array}{c}\text { Mean } \\
\text { (lb. oz.) }\end{array}$ & $\begin{array}{l}\text { S.D. } \\
\text { (oz.) }\end{array}$ \\
\hline $29+30$ & 13 & 6 & 7 & 3 & $27 \cdot 72$ & $2 \cdot 00$ & $10 \cdot 92$ & $0 \cdot 79$ & $26 \cdot 72$ & $1 \cdot 64$ & $10 \cdot 53$ & $0 \cdot 65$ & 1,476 & 268 & 3 & 9 \\
\hline $31+32$ & 13 & 8 & 5 & .2 & $28 \cdot 38$ & $1 \cdot 81$ & $11 \cdot 18$ & $0 \cdot 74$ & $27 \cdot 22$ & $1 \cdot 57$ & $10 \cdot 72$ & $0 \cdot 62$ & 1,616 & 254 & 9 & 9 \\
\hline $33+34$ & 24 & 14 & 10 & 12 & $30 \cdot 34$ & $1 \cdot 51$ & $11 \cdot 96$ & 0.59 & $28 \cdot 58$ & $1 \cdot 29$ & $11 \cdot 26$ & 0.51 & 1,894 & 294 & 3 & 10 \\
\hline $35+36$ & 41 & 18 & 23 & 10 & $31 \cdot 59$ & $1 \cdot 46$ & $12 \cdot 45$ & 0.57 & $30 \cdot 47$ & $1 \cdot 98$ & $12 \cdot 01$ & 0.78 & 2,272 & 498 & 0 & 18 \\
\hline 37 & 28 & 6 & 22 & 8 & $32 \cdot 61$ & $1 \cdot 68$ & $12 \cdot 85$ & 0.66 & $31 \cdot 51$ & $2 \cdot 23$ & $12 \cdot 42$ & 0.88 & 2,696 & 630 & 15 & 22 \\
\hline F.T. & 209 & 0 & 209 & 4 & $33 \cdot 90$ & $1 \cdot 26$ & $13 \cdot 32$ & 0.50 & $33 \cdot 59$ & $1 \cdot 36$ & $13 \cdot 22$ & 0.54 & 3,323 & 423 & 5 & 15 \\
\hline F.T. & 243 & 243 & 0 & 2 & $34 \cdot 60$ & $1 \cdot 39$ & $13 \cdot 63$ & 0.55 & $34 \cdot 26$ & $1 \cdot 55$ & $13 \cdot 45$ & 0.62 & 3,435 & 514 & 7 & 18 \\
\hline
\end{tabular}


the mixed group of all birth-ranks comprising the present full term series where the mean birth weight is $7.56 \mathrm{lb}$. Allowance must, however,

TABLE 2

Mean Birth Weights of First-born Infants* BY Social Class

\begin{tabular}{cc|c|c|c|c|c|c}
\hline & & \multicolumn{2}{|c|}{ Males } & & \multicolumn{2}{|c|}{ Females } \\
\cline { 4 - 7 } Class & No. & $\begin{array}{l}\text { Mean } \\
\text { (lb.) }\end{array}$ & $\begin{array}{l}\text { S.D. } \\
\text { (lb.) }\end{array}$ & No. & $\begin{array}{l}\text { Mean } \\
\text { (lb.) }\end{array}$ & $\begin{array}{l}\text { S.D. } \\
\text { (lb.) }\end{array}$ \\
\hline III &.. & 222 & $7 \cdot 38$ & 0.968 & 175 & $7 \cdot 31$ & 0.884 \\
\hline IV & $\ldots$ & 111 & $7 \cdot 30$ & 1.027 & 106 & $7 \cdot 25$ & 0.820 \\
\hline V &.. & 58 & 6.96 & 0.989 & 58 & 6.89 & 0.890 \\
\hline
\end{tabular}

* Born in Simpson Memorial Maternity Pavilion, Royal Infirmary' Edinburgh, 1940.

be made for the possible effect of improved social conditions since 1940, which in Scotland have probably affected Class III to a greater extent than Class V.

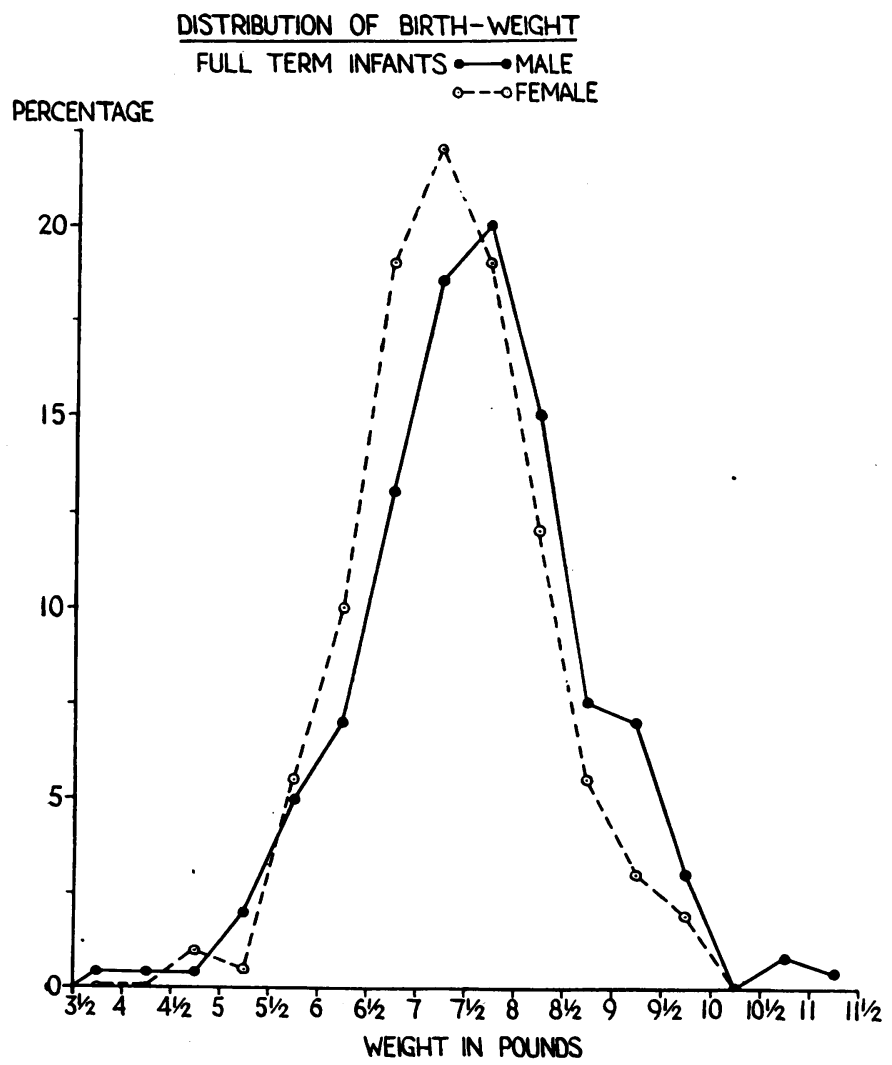

FIG. 2
The means for occipitofrontal head circumference correspond closely with the composite means given by Meredith (1946) for 2,484 white full term males $(34 \cdot 5 \mathrm{~cm}$.) and 2,483 white full term females $(33 \cdot 9 \mathrm{~cm}$.).

The crown-heel length, which was measured in 238 full term males and 206 full term females of the present series, was $50.71 \pm 1.95 \mathrm{~cm}$. $(19.98 \pm$ 0.77 in.) and $49 \cdot 80 \pm 2 \cdot 084 \mathrm{~cm} .(19 \cdot 62 \pm 0 \cdot 82$ in.) respectively, which may be compared with Stuart and Stevenson's (1950) percentile rating 50 for $50.6 \mathrm{~cm}$. (19.9 in.) males, and $50.2 \mathrm{~cm}$. $(19.8$ in.) females. Since Meredith's figures were based entirely on North American studies and Stuart's were obtained in Boston, it is of some interest to find how closely these correspond with the Edinburgh figures.

The distribution curves for the three measurements other than crown-heel length are shown in Figs. 2, 3 and 4. These bring out an important point in defining criteria of prematurity, viz. that a small proportion of full term infants are likely to fall within any arbitrary standard of prematurity based on a single measurement. In spite of minor irregularities, the distribution curve is in each case approximately a normal one, such as might be expected for the same measurements at other ages if pathological cases are excluded.

\section{Criteria of Prematurity}

The present data illustrate the fact that there is bound to be considerable overlap in the measurements of the smaller full term infants and the larger premature infants approaching term. Any arbitrary measurement which is designed to be of clinical value in indicating prematurity will be exceeded by a proportion of infants of more than 36 weeks' gestation, while a proportion of full term infants will fall below it. It is also likely that the latter objection will apply unequally to the two sexes, since newborn females are on the average smaller than males of the same gestational age, although it is possible that the greater variability in males observed in the present series may, to some extent, offset the sex difference. Ideally, it would be desirable to define separate criteria of prematurity for males and females, and for infants of different birth-rank, but at the present time this appears impracticable, since the introduction of multiple standards 


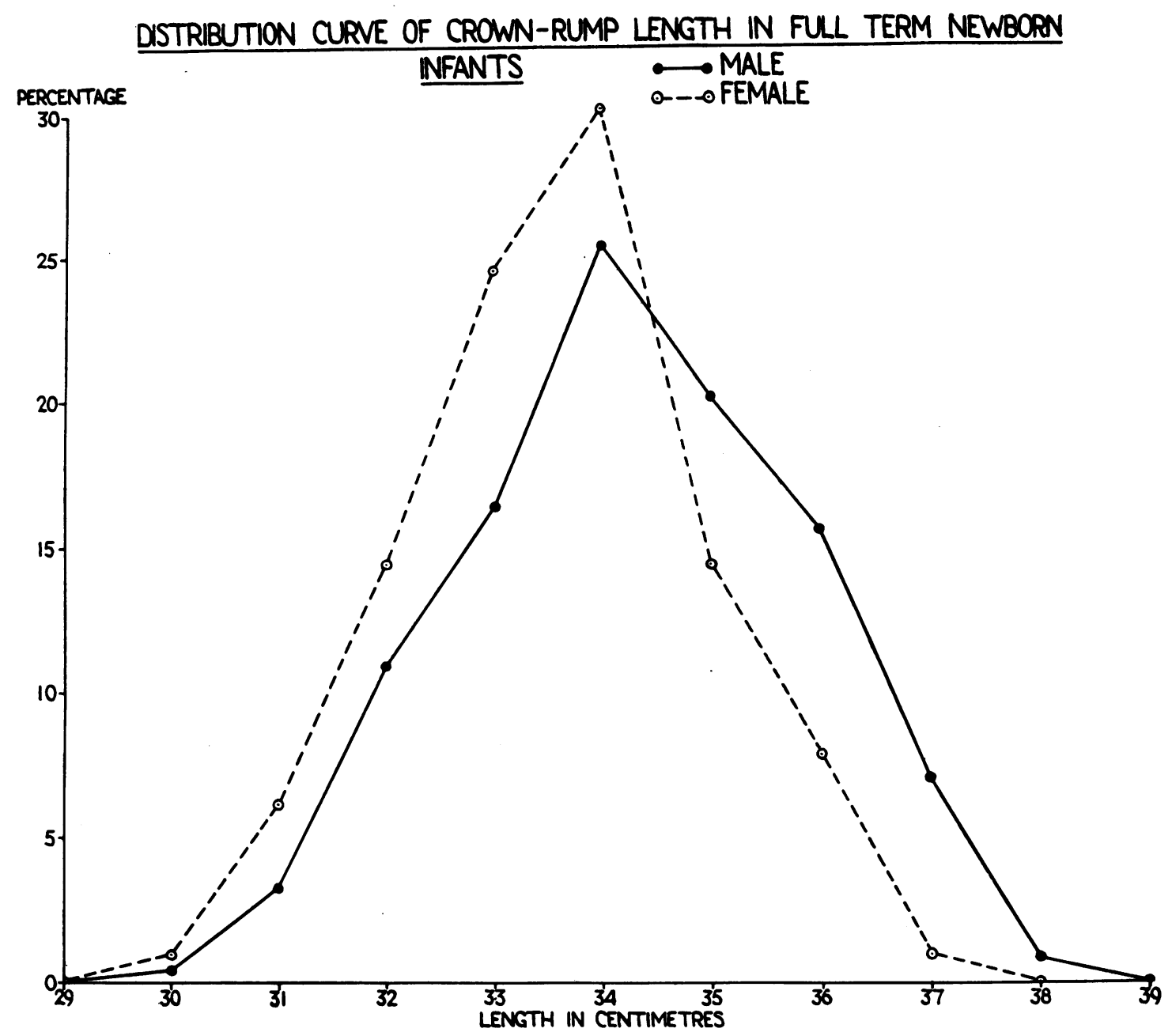

FIG. 3

would further complicate an issue which is by no means clear.

The present series of full term infants ( 243 males, 209 females) shows the following percentages of males and females falling below certain arbitrary measurements (Table 3). (In the case of crownheel length, the figures are based on 238 males and 206 females, and are not strictly comparable with the other measurements owing to the omission of eight of the smaller infants.)

In the case of premature infants, it was obvious that the proportion of infants of 37 weeks' gestation exceeding any useful standard was so high that any reliable assessment of prematurity in this age group could only be made on determination of gestational age. Since for practical purposes the infants in whom a diagnosis of prematurity is most necessary are those of less than 36 weeks gestation, it was decided to examine the 29 premature infants of 34 and 35 weeks' gestation to determine the percentage in whom the measurements exceeded those given above (Table 4). In this analysis it must be borne in mind that the total group is small and represents surviving prematures only; the percentages would presumably be smaller if stillbirths and neonatal deaths were included.

The possible criteria of prematurity may, therefore, be considered on the basis of the misfits, i.e. the proportion of full term infants which they will include, and the proportion of infants of less than 36 weeks' gestation which they will fail to identify.

Birth Weight. The birth weight standard of 2,500 g. $\left(5 \frac{1}{2} \mathrm{lb}\right.$.) is firmly established, and no alteration should be made without good reason. It has been 
TABle 3

Percentage of Full Term Infants Falling Below Certain Measurements

\begin{tabular}{|c|c|c|c|c|c|}
\hline \multirow[b]{2}{*}{ Birth weight } & \multirow{2}{*}{\multicolumn{3}{|c|}{$\begin{array}{c}\left.\text { Less } \operatorname{than}_{\left(5 \frac{1}{2}\right.} 1 \mathrm{lb} .\right) \\
\text {. }\end{array}$}} & Males & Females \\
\hline & & & & $3 \cdot 2$ & $1 \cdot 4$ \\
\hline $\begin{array}{l}\text { Crown-rump } \\
\text { length }\end{array}$ & $\begin{array}{r}\text { Less } \\
\text {, } \\
\text { ", }\end{array}$ & $\begin{array}{cc}\text { than } & 30 \\
\text {, } & 31 \\
\text {, } & 32 \\
\text {, } & 33\end{array}$ & $\begin{array}{l}\text { m. } \\
\text { ", }\end{array}$ & $\begin{array}{r}0 \\
1 \cdot 2 \\
4 \cdot 8 \\
13 \cdot 2\end{array}$ & $\begin{array}{r}0 \cdot 5 \\
3 \cdot 5 \\
8 \cdot 2 \\
26 \cdot 4\end{array}$ \\
\hline $\begin{array}{l}\text { Head } \\
\text { circumference }\end{array}$ & ", & $\begin{array}{ll}, & 31 \\
, & 32 \\
, & 33\end{array}$ & $\begin{array}{l}\text {," } \\
\text { ", }\end{array}$ & $\begin{array}{r}0 \\
2 \cdot 4 \\
10 \cdot 8\end{array}$ & $\begin{array}{r}1 \cdot 0 \\
7 \cdot 2 \\
21 \cdot 6\end{array}$ \\
\hline $\begin{array}{l}\text { Crown-heel } \\
\text { length }\end{array}$ & ", & $\begin{array}{ll}\text {, } & 45 \\
, & 46 \\
, & 47\end{array}$ & ", & $\begin{array}{r}0 \\
0 \cdot 8 \\
1 \cdot 6\end{array}$ & $\begin{array}{l}0.5 \\
1.9 \\
4 \cdot 3\end{array}$ \\
\hline
\end{tabular}

TABLE 4

Percentage of Surviving Premature Infants of 34 AND 35 WeEks EXCEEDING CertaIN MEASUREMENTS *

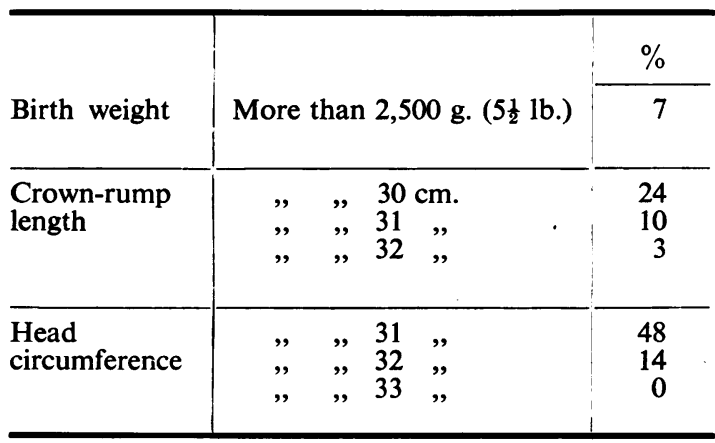

* The measurements of crown-heel length were too few in this series for separate analysis.

\section{DISTRIBUTION CURVE OF O.F. HEAD-CIRCUMFERENCE IN FULL TERM NEWBORN INFANTS}

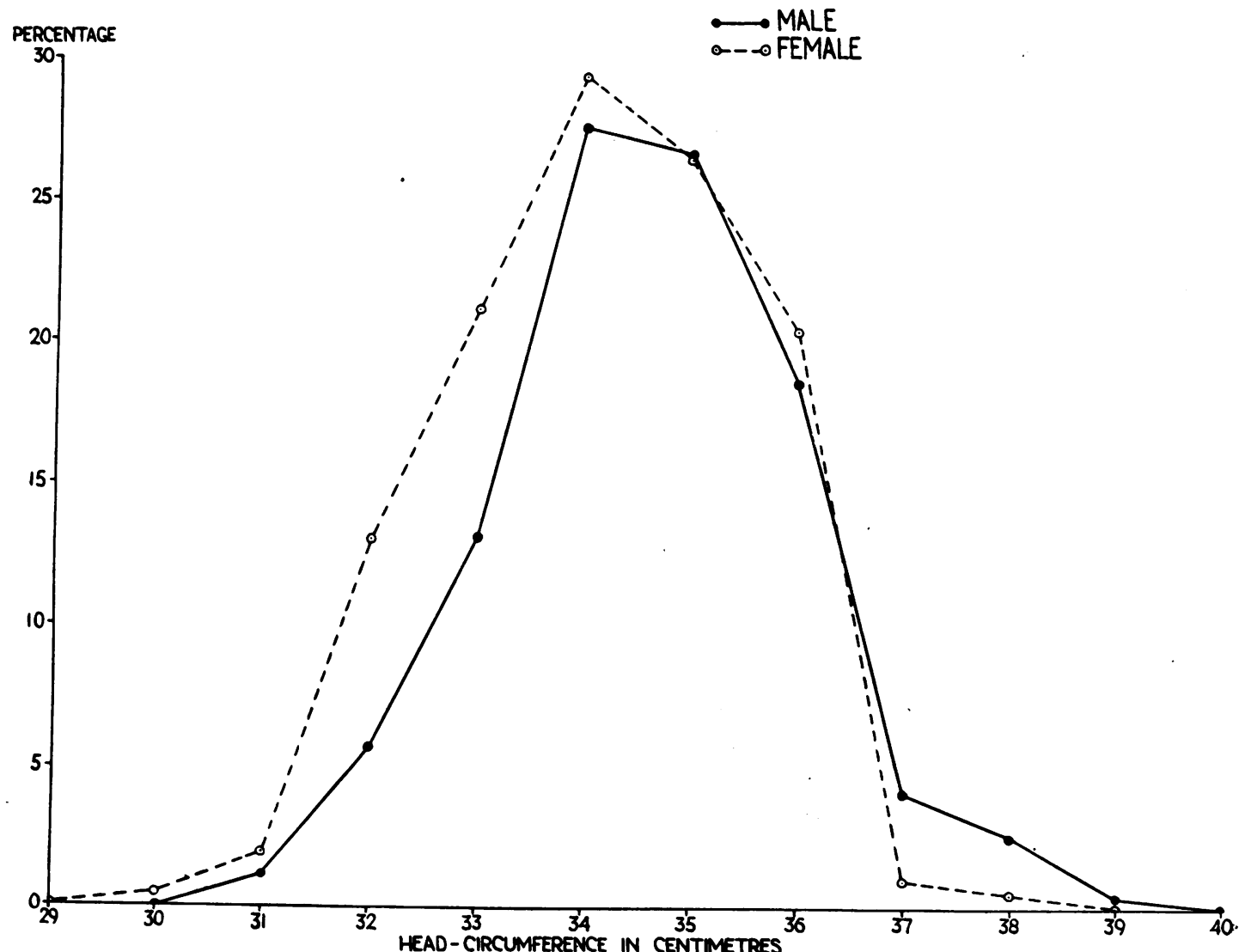

Fig. 4 
suggested (Reardon et al., 1951) that the standard is too high, but while it is certainly true that many infants of 5 to $5 \frac{1}{2} \mathrm{lb}$. can be nursed and fed as though they were full term, it will be seen from Table 1 that the mean birth weight of infants of 37 weeks' gestation was in fact over $5 \frac{1}{2} \mathrm{lb}$., and from Table 3 that two out of 29 infants of less than 36 weeks' gestation exceeded this weight. It is considered that for white infants the $5 \frac{1}{2} \mathrm{lb}$. standard is as satisfactory as any, and in the present series includes only a relatively small proportion of full term infants. This latter observation is confirmed by Thomson's (1951) data obtained in Aberdeen. Using a stricter definition of full term, viz. $280 \pm 7$ days gestation, he found that of full term infants, excluding twins, born to 766 primiparous women $2.6 \%$ were below $5 \frac{1}{2} \mathrm{lb}$. in birth weight.

Crown-Rump Length. Since no standard measurement is in general use, a wider range of measurements has been reviewed. Of these, it is considered

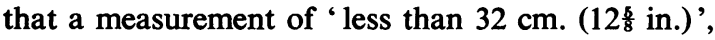
or alternatively ' $12 \frac{1}{2}$ in. or less' would probably provide the best standard. This will include less than $10 \%$ of full term infants, and exclude less than $5 \%$ of prematures of less than 36 weeks' gestation.

From the formula $\mathrm{CR}=0.66 \mathrm{CH}+0.5$ (see below) it may be assumed that a crown-rump length of $32 \mathrm{~cm}$. corresponds to a crown-heel length of $47 \cdot 2 \mathrm{~cm}$. Since a crown-heel length of less than $47 \mathrm{~cm}$. is already widely used as a standard of prematurity, a crown-rump length of less than $32 \mathrm{~cm}$. provides a closely comparable standard.

Head Circumference. Most authors who have included head circumference in their standards of prematurity have used 'less than $33 \mathrm{~cm}$. (13 in.)', which has the advantage of providing a convenient point on the metric and British lineal scale. The present data indicate that this measurement has the disadvantage of including a relatively large number of full term infants $(12 \%$ males, $21 \%$ females). On the other hand, no infants of less than 36 weeks' gestation were found to exceed this measurement, whereas $13 \cdot 8 \%$ exceeded $32 \mathrm{~cm}$. It is therefore recommended that the standard 'less than $33 \mathrm{~cm}$. (13 in.)' should be retained as one indication of prematurity.

Combined Standard. Where the three measurements discussed above are used, and the gestational age is unknown, an infant showing two of the three criteria, viz. birth weight $2,500 \mathrm{~g}$. or less, crownrump length of less than $32 \mathrm{~cm}$. and head circumference of less than $33 \mathrm{~cm}$. may reasonably be regarded as premature. The error will be less than when a single measurement is relied on, but will not be entirely eliminated.

\section{Correlation of Measurements and Frequency Distribution}

In a study of the correlation of birth weight and crown-rump length with gestational age, it is frequently stated that total length provides a better index of gestational age than does birth weight (e.g. Crosse, 1945). In order to see whether this applies to crown-rump length in the present series of premature infants, regression coefficients were calculated for 27 .males and 26 females of 29 to 37 weeks' gestation. Twins were omitted from this series. The sexes were analysed separately in the first instance, but as the differences between the two were not significant, the calculations were subsequently made on the combined group.

It was found that the crown-rump measurement had almost exactly the same correlation, namely 0.60 , with week of gestation as that between weight and week of gestation, namely $0 \cdot 61$. (Expressed in terms of regression coefficients, the 'expected' crown-rump length for a 30 week infant was $267 \mathrm{~mm}$. increasing by $4.6( \pm 0.9) \mathrm{mm}$. per week, and the ' expected' weight for a 30 week infant was $3 \mathrm{lb}$. $6 \mathrm{oz}$. increasing by $2.6( \pm 0.5)$ per week.) In the present series, therefore, weight and crown-rump length appeared to be of equal value in the assessment of gestational age.

For any given length of gestation, the correlation between any two of the three measurements, viz. weight, head circumference, and crown-rump length was found to be approximately $0 \cdot 8$, but in the light of other data on full term infants this correlation is probably a slight over-estimate due to sampling error. A number of authors have given formulae based on measurements of length for the calculation of gestational age. These range from the more elaborate one of Scammon and Calkins (1924, 1929), viz.

$$
\begin{gathered}
\mathrm{T} \text { (age in lunar months) }=2 \cdot 3+\frac{2 \cdot 5 \mathrm{CH}}{28}+\frac{(\mathrm{CH})^{2}}{784} \\
\text { or } \\
\mathrm{T}=2 \cdot 23+\frac{\mathrm{CR}}{7 \cdot 56}+\left(\frac{\mathrm{CR}}{18 \cdot 49}\right)^{2}
\end{gathered}
$$

(where $\mathrm{CH}$, crown-heel length, and $\mathrm{CR}$, crown-rump length, are measured in $\mathrm{cm}$.), to the sublimely simple one of Crosse (1945), viz.

$\mathrm{T}$ (age in weeks) $=\mathrm{CH}$ (in inches) $\times 2$

Obviously the first of these could only be used for clinical purposes by means of a nomogram, and in view of the correlation found above it is doubtful if such elaborate formulae are justified in clinical assessment. Since the crown-rump length is approximately two-thirds of the crown-heel length 
(see below), Crosse's formula was rewritten as follows:

$T$ (age in weeks) $=C R$ (in inches) $\times 3$

and applied to 100 consecutive prematures in the present series. It was found that this formula gave the age in weeks with an error of two weeks or less in $65 \%$ of cases, and with an error of three weeks or less in $84 \%$ of cases, and corresponded very closely with the results obtained from the formula $\mathrm{T}=\mathrm{CH}$ (in inches) $\times 2$ in the 30 cases in which crown-heel length was also available. As a rule of thumb, this is probably as satisfactory as many used in clinical medicine.

In a correlation of measurements in twins, 19 pairs of twins of like sex, of 32 to 40 weeks' gestation, were examined in order to determine in which measurement the pairs resembled each other most closely. By this means differences due to sex and possible errors in estimation of gestational age were eliminated, since it could be assumed that the two members of a twin pair would be of identical age.

The 'intra-class' correlation coefficient was calculated for each variable, with the following results:

\begin{tabular}{|c|c|}
\hline & 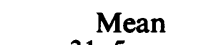 \\
\hline ferer & $\begin{array}{l}31.5 \mathrm{~cm} . \\
29.2 \mathrm{~cm} . \\
4 \mathrm{lb} .9 \mathrm{cz}\end{array}$ \\
\hline
\end{tabular}

These correlations do not differ significantly among themselves. From the twin figures one could predict that in $95 \%$ of cases members of a twin pair in this age range would not differ from each other by more than $2 \cdot 2 \mathrm{~cm}$. head circumference, $2 \cdot 7$ crown-rump length, and $22 \mathrm{oz}$. weight.

A study of the relationship of crown-rump length to crown-heel length was made. Since crown-heel length has been used to a much greater extent in clinical measurement than crown-rump length, it was decided to compare the measurements in both premature and full term infants to determine the relationship between the two.

In 30 premature infants of 35 to 37 weeks' gestation (where the effect of gestational age may be regarded as minimal), the relationship was estimated as follows. Denoting the $\mathrm{CR}$ in $\mathrm{cm}$. by $y$ and the $\mathrm{CH}$ by $\mathrm{x}$, the equation for predicting $y$ from $x$ was found from the data to be:

$$
\check{y}=0.686 x-0.60
$$

The mean values for $y$ and $x$ were $32.20 \mathrm{~cm}$. and $47.82 \mathrm{~cm}$. respectively.

In the above equation, the gradient of the line of regression coefficient of $0.686( \pm 0.095)$ does not differ significantly from Scammon and Calkins' (1929) value of $0 \cdot 66$. Using their value the relationship becomes:

$$
\begin{aligned}
\check{y} & =0.66(x-47 \cdot 82)+32 \cdot 20 \\
& =0.66 x+0.6
\end{aligned}
$$

This agrees remarkably closely with Scammon and Calkins' equation:

$$
\mathrm{CR}=0.66 \mathrm{CH}+0.5
$$

While an element of chance presumably enters into

\begin{tabular}{|c|c|c|c|c|c|c|c|c|c|c|c|c|c|c|c|c|c|c|c|c|}
\hline \multicolumn{2}{|c|}{ Weight (lb.) } & $\cdots$ & .. & $3 \frac{1}{2}$ & 4 & $4 \frac{1}{2}$ & 5 & $5 \frac{1}{2}$ & 6 & $6 \frac{1}{2}$ & 7 & $7 \frac{1}{2}$ & 8 & $8 \frac{1}{2}$ & 9 & $9 \frac{1}{2}$ & 10 & $10 \frac{1}{2}$ & 11 & Total \\
\hline $\begin{array}{l}\text { Males } \\
\text { Females }\end{array}$ & $\begin{array}{l}\cdots \\
\cdots \\
\end{array}$ & $\begin{array}{l}\cdots \\
\cdots\end{array}$ & $\begin{array}{l}\cdots \\
\cdots\end{array}$ & 1 & 1 & $\begin{array}{l}1 \\
2\end{array}$ & $\begin{array}{l}5 \\
1 \\
\end{array}$ & $\begin{array}{l}11 \\
12\end{array}$ & $\begin{array}{l}17 \\
20\end{array}$ & $\begin{array}{l}31 \\
40\end{array}$ & $\begin{array}{l}45 \\
46\end{array}$ & $\begin{array}{l}49 \\
40\end{array}$ & $\begin{array}{l}36 \\
26 \\
\end{array}$ & $\begin{array}{l}18 \\
12\end{array}$ & $\begin{array}{r}17 \\
6\end{array}$ & $\begin{array}{l}8 \\
4\end{array}$ & $\begin{array}{l}0 \\
-\end{array}$ & 2 & 1 & $\begin{array}{l}243 \\
209\end{array}$ \\
\hline $\begin{array}{r}\text { Head cir } \\
\text { nearest }\end{array}$ & $\begin{array}{l}\text { cumf } \\
\text { cm.) }\end{array}$ & $\begin{array}{l}\text { ence } \\
\cdots \\
\end{array}$ & (to & & & & 30 & 31 & 32 & 33 & 34 & 35 & 36 & 37 & 38 & 39 & - & - & - & Total \\
\hline $\begin{array}{l}\text { Males } \\
\text { Females }\end{array}$ & $\begin{array}{l}\cdots \\
\cdots\end{array}$ & $\begin{array}{l}\cdots \\
\cdots\end{array}$ & $\cdots$ & & & & -1 & $\begin{array}{l}3 \\
4\end{array}$ & $\begin{array}{l}14 \\
27 \\
\end{array}$ & $\begin{array}{l}32 \\
44\end{array}$ & $\begin{array}{l}67 \\
61\end{array}$ & $\begin{array}{l}65 \\
55\end{array}$ & $\begin{array}{l}45 \\
14 \\
\end{array}$ & $\begin{array}{r}10 \\
2\end{array}$ & $\begin{array}{l}6 \\
1\end{array}$ & 1 & - & - & - & $\begin{array}{l}243 \\
209 \\
\end{array}$ \\
\hline $\begin{array}{l}\text { Crown-ru } \\
\text { (to nea }\end{array}$ & mp: & & . & & & & 30 & 31 & 32 & 33 & 34 & 35 & 36 & 37 & 38 & - & - & - & - & Total \\
\hline $\begin{array}{l}\text { Males } \\
\text { Females }\end{array}$ & $\begin{array}{l}\cdots \\
\cdots\end{array}$ & $\begin{array}{l}\cdots \\
\cdots \\
\end{array}$ & $\cdots$ & & & & $\begin{array}{l}1 \\
2\end{array}$ & $\begin{array}{r}8 \\
13\end{array}$ & $\begin{array}{l}26 \\
30\end{array}$ & $\begin{array}{l}40 \\
51\end{array}$ & $\begin{array}{l}62 \\
63\end{array}$ & $\begin{array}{l}49 \\
30\end{array}$ & $\begin{array}{l}38 \\
18\end{array}$ & $\begin{array}{r}17 \\
2\end{array}$ & $\underline{2}$ & - & $\overline{-}$ & - & - & $\begin{array}{l}243 \\
209\end{array}$ \\
\hline $\begin{array}{l}\text { Crown-he } \\
\text { (to nea }\end{array}$ & $\begin{array}{l}\text { el: } \\
\text { rest }\end{array}$ & & $\cdots$ & & & 45 & 46 & 47 & 48 & 49 & 50 & 51 & 52 & 53 & 54 & 55 & 56 & 57 & - & Total \\
\hline $\begin{array}{l}\text { Males } \\
\text { Females }\end{array}$ & $\begin{array}{l}\cdots \\
\cdots\end{array}$ & $\begin{array}{l}\cdots \\
\cdots\end{array}$ & $\cdots$ & & & $\begin{array}{l}1 \\
2\end{array}$ & $\begin{array}{l}2 \\
6\end{array}$ & $\begin{array}{r}7 \\
10\end{array}$ & $\begin{array}{l}18 \\
20\end{array}$ & $\begin{array}{l}29 \\
43\end{array}$ & $\begin{array}{l}30 \\
38\end{array}$ & $\begin{array}{l}68 \\
52\end{array}$ & $\begin{array}{l}51 \\
24\end{array}$ & $\begin{array}{r}16 \\
5\end{array}$ & $\begin{array}{r}11 \\
3\end{array}$ & $\begin{array}{l}3 \\
3\end{array}$ & $\begin{array}{c}1 \\
-\end{array}$ & 1 & - & $\begin{array}{l}238 \\
206\end{array}$ \\
\hline
\end{tabular}
such a singularly close agreement, it can at least

TABLE 5

FreQuency Distributions 
be said that the present data are certainly consistent with Scammon and Calkins' formula. In the case of 238 male and 206 female full term infants (see below), the present data were also consistent with the same formula.

A correlation of measurements in full term infants was made.

The frequency distributions of each of four measurements, viz. birth weight, head circumference, crown-rump length, and crown-heel length were calculated for 243 males and 209 females in the case of the first three measurements, and on 238 males and 206 females in the case of crown-heel length. A distribution range of $\frac{1}{2} \mathrm{lb}$. was used in the case of weight (i.e. $3 \frac{1}{2} \mathrm{lb}$. to $3 \mathrm{lb}$. $15 \frac{3}{4}$ oz.; $4 \mathrm{lb}$. to $4 \mathrm{lb}$. $73 \mathrm{oz}$. etc.). In the case of the three linear measurements, an interval of $0.5 \mathrm{~cm}$. was used in the first instance, but in view of the irregularity of the figures, a coarser grouping $(1 \mathrm{~cm}$.) was substituted and allowance made for this in the subsequent calculations.

In Table 5 the frequency distributions are shown with an interval of $\frac{1}{2} \mathrm{lb}$. in the case of weight and to the nearest $\mathrm{cm}$. in the case of linear measurements.

For each variable and each sex, the mean and dispersion, as measured by the standard deviation, has been calculated. A comparison of the two sexes shows that for all four variables the males are more variable than the females.

The correlation coefficients were calculated for the infants for which all four measurements were available, viz. 238 males and 206 females.

TABLE 6

Correlation Coefficients*

\begin{tabular}{|c|c|c|c|c|c|}
\hline \multicolumn{5}{|c|}{ Correlations based on 238 males. } & \multirow[b]{2}{*}{ Wt. } \\
\hline & & $\mathrm{HC}$ & CR & $\mathrm{CH}$ & \\
\hline $\begin{array}{l}\mathrm{HC} \\
\mathrm{CR} \\
\mathrm{CH} \\
\mathrm{Wt}\end{array}$ & $\begin{array}{l}\ldots \\
\ldots \\
\ldots\end{array}$ & $\begin{array}{l}-\overline{0} .565 \\
0.582 \\
0.649\end{array}$ & $\begin{array}{l}0.565 \\
\overline{0} \\
0.813 \\
0.724\end{array}$ & $\begin{array}{c}0.582 \\
0.813 \\
-\overline{0} \\
0.767\end{array}$ & $\begin{array}{c}0.649 \\
0.724 \\
0.767 \\
-\end{array}$ \\
\hline $\begin{array}{l}\text { Corr } \\
\text { HC } \\
\text { CR } \\
\text { CH } \\
\text { Wt }\end{array}$ & $\begin{array}{l}\text { 'lati } \\
\cdots \\
\cdots \\
\cdots \\
\cdots\end{array}$ & $\begin{array}{l}\text { ns based } \\
0.473 \\
0.458 \\
0.520\end{array}$ & $\begin{array}{l}206 \text { fem } \\
0.473 \\
-\overline{0.798} \\
0.729\end{array}$ & $\begin{array}{l}0.458 \\
0.798 \\
\overline{0.689}\end{array}$ & $\begin{array}{l}0.520 \\
0.729 \\
0.689 \\
-\quad\end{array}$ \\
\hline \multicolumn{5}{|c|}{\begin{tabular}{l}
\multicolumn{4}{c}{ Correlations averaged for both sexes. } \\
HC
\end{tabular}} & $\begin{array}{l}0.593 \\
0.726 \\
0.733 \\
-\end{array}$ \\
\hline
\end{tabular}

* HC denotes head circumference, CR crown-rump length, $\mathrm{CH}$ crown-heel length, and Wt. weight.
The relative magnitudes of the correlation coefficients are what might be expected. Those for females are less than those for males but the difference can reasonably be ascribed to sampling error, so that the two sexes have been averaged.

The highest correlation is that between $\mathrm{CR}$ and $\mathrm{CH}$ (approximately $0 \cdot 80$ ). Either of these correlates fairly highly with weight but less so with head circumference. Of all four variables, head circumference has the smallest correlations; it correlates better with weight than with $\mathrm{CR}$ or $\mathrm{CH}$. The data are consistent with the formula predicting $\mathrm{CR}$ from $\mathrm{CH}$, namely $\mathrm{CR}=0.66 \mathrm{CH}+0.5$.

\section{Summary and Conclusions}

Measurements of occipitofrontal head circumference, crown-rump length and birth weight have been made on 119 living premature infants of 29 to 37 weeks' gestation inclusive, and on 243 male and 209 female full term infants. Crown-heel length was measured on 30 premature infants, and on 238 male and 206 female full term infants. The means and standard deviations for groups of increasing gestational age are presented, and the frequency distributions and correlations for each measurement are given in the case of full term infants.

The practical application of each measurement to living infants is discussed. It is suggested that crown-rump length might usefully be included in the routine measurement of infants where facilities are available, and it is emphasized that this measurement has certain advantages over that of crown-heel length in the case of premature infants. The relationship of crown-rump and crown-heel length (measured in $\mathrm{cm}$.) was found in both premature and full term infants to be consistent with the formula of Scammon and Calkins (1929):

$$
\mathrm{CR}=0.66 \mathrm{CH}+0.5
$$

The criteria of prematurity have been discussed. The following arbitrary measurements were found to fit the data sufficiently well to be of clinical value: head circumference less than $33 \mathrm{~cm}$. (13 in.); crown-rump length less than $32 \mathrm{~cm}$. (125 in.) or alternatively $12 \frac{1}{2}$ in. or less; birth weight $2,500 \mathrm{~g}$. ( $5 \frac{1}{2} \mathrm{lb}$.) or less. It is emphasized that any single arbitrary standard is likely to include a proportion of full term infants and exclude a proportion of prematures of over 36 weeks' gestation. The proportion of misfits will be reduced by using three or more measurements in combination, together with gestational age when this is known. Although it does not at present appear practicable to recommend different standards of prematurity for males and females, the proportion of misfits will be affected by sex. 
The correlations of birth weight and crown-rump length to week of gestational age in premature infants were found to be almost identical, viz. 0.61 and 0.60 respectively.

In 19 pairs of twins of like sex, the intra-class correlation of head circumference was 0.86 , of crown-rump length 0.79 , and of birth weight $0 \cdot 80$. These correlations do not differ significantly among themselves.

In singleton premature infants of the same week of gestational age, the correlation between any two of the three' measurements was approximately $0 \cdot 80$.

In full term infants, the highest correlation was found between crown-heel and crown-rump length, both of which measurements correlated highly with weight. The correlations were smallest in the case of head circumference.

I am much indebted to Drs. C. W. Walker, W. Taylor, W. Gillies, P. G. MacGillivray, and H. T. Swan for their cooperation in obtaining the measurements; to Dr. John Thomson for the data included in Table 2, and for the design of the measuring board; and to Miss J. Thomson, of the Department of Social Medicine, University of Edinburgh, for the computations involved in Table 1.

\section{REFERENCES}

Bakwin, H., and Bakwin, R. M. (1934). Hum. Biol., 6, 612 .

(1934). Amer. J. Dis. Child., 48, 1234.
Barcroft, J. (1946). In 'Child Health and Development,' ed. R. W. B. Ellis, pp. 39-60. London.

Calkins, L. A. (1922). Amer. J. Obstet. Gynec., 4, 109.

Crosse, V. M. (1945). ' 'The Premature Baby.' London.

Dunham, E. C. (1948). 'Premature infants.' Washington, D.C.

Grulee, C. G., and Sanford, H. N. (1948). In Brennemann's ' Practice of Pediatrics,' ed. I. McQuarrie, Vol. 1, ch. 42, p. 19.

Hamilton, W. J., Boyd, J. D., and Mossman, H. W. (1945). 'Human Embryology' p. 88. Cambridge.

Meredith, H. V. (1946). Child development, 17, 1.

Moloy, H. C. (1942). Amer. J. Obstet. Gynec., 44, 762.

Peckham, C. H. (1938). J. Pediat., 13, 474.

Potter, E. L., and Adair, F. L." (1949). "Fetal and Neonatal Death.' Chicago.

Reardon, H., Wilson, J. L., and Graham, B. (1951). Amer. J. Dis. Child., 81, 99.

Reiche, A. (1916). $\quad Z$. Kinderheilk., 13, 332.

Scammon, R. E., and Calkins, L. A. (1924). Proc. Soc. exp. Biol., N.Y., $21,549$.

- - (1929). 'Development and Growth of the External Dimensions of the Human Body in the Fetal Period.' Minneapolis.

Streeter, G. L. (1920). Contr. Embryol. Carneg. Instn. Publ. No. 55, 11, 143. (Publ. no. 274.)

Steiner, M., and Pomerance, W. (1950). Pediatrics, 6, 872 .

Stuart, H. C., and Stevenson, S. S. (1950). In MitchellNelson Textbook of Pediatrics, 5th ed., ed. W. E. Nelson, pp. 14-73. Philadelphia and London:

Thomson, A. M. (1951). Brit.J. Nutrit., 5, 158.

Ylppö, A. (1919). Z. Kinderheilk., 24, 111. 